\title{
Colour or no colour in the juvenile shell of the black lip pearl oyster, Pinctada margaritifera?
}

\author{
Nolwenn TRINKLER ${ }^{1}$, Gilles Le MOULLAC ${ }^{2}$, Jean-Pierre CUIF ${ }^{1}$, Nathalie COCHENNEC-LAUREAU ${ }^{3}$ \\ and Yannicke DAUPHIN ${ }^{1, a}$ \\ ${ }^{1}$ UMR IDES 8148, Bât. 504, Université Paris Sud, 91405 Orsay Cedex, France \\ ${ }^{2}$ IFREMER, Centre du Pacifique, BP 7004, 98719 Taravao, French Polynesia \\ ${ }^{3}$ IFREMER, Centre de Nantes, BP 21105, Nantes, France
}

Received 25 October 2011; Accepted 1st February 2012

\begin{abstract}
Pinctada margaritifera mollusc is cultivated in French Polynesia for the production of black pearls. For this study, the colour of juvenile samples (48 days old) was investigated in the visible range spectra (430-700 $\mathrm{nm}$ ) using spectrophotometry. A first measurement was done with the soft parts still inside the shell (entire animal). Then, the soft parts were removed in order to do a second measurement on the growing edge of the shell. Comparison of the two measurements shows that the estimation of the living animal colour with unaided eye is strongly influenced by the colour of the soft parts. The use of the International Commission on Illumination (ISI) chromaticity diagram shows that at this growth stage, the shells are "white"; i.e. present no absorptions to the visible part. Multivariate statistical analyses based on the intensities of 6 wavelengths show that the shell colour is less variable than the colours of the entire animals. Wavelength intensities of the shells are similar, so no colour trend is visible. On the other hand, the colours of the entire animals are darker, and more variable. At this growth stage, the shell colour is not predictable for a potential selection of receiver or donor.
\end{abstract}

Key words: Juvenile shell / Colour-scoring / Mollusc / Pearl oyster / Pinctada margaritifera

\section{Introduction}

The bivalve Pinctada margaritifera, also called the black lip pearl oyster, is cultivated mainly in French Polynesia for the production of dark coloured pearls (principally black). The black pearl production relies exclusively on the collection of wild spat of $P$. margaritifera. We will adopt the widely used term "pearl oyster", despite from a taxonomical point of view Pinctada does not belong to Ostreidae. These cultured pearls are the product of grafting and rearing of this mollusc in the natural environment. The grafts are made by a surgical operation during which the graft (i.e., a small piece of the epithelium mantle edge) is inserted into the "pearl pocket" in the reproductive tissue of the receiving oyster with a bead (i.e., a sphere made from the inner part of another shell) known as the nucleus (Cochennec-Laureau et al. 2010). The usual process is to select the shells with the darkest inner nacreous layer,

\footnotetext{
a Corresponding author: yannicke.dauphin@u-psud.fr
}

assuming they have the darkest mantle, "to ensure" the production of dark coloured (preferably black) cultured pearls. Actually, the darkest coloured of these pearls are the most demanded. Thus, colour is an important factor to consider because it qualifies pearls and affects their price. However, the commercial success of the "black" pearls is dependent on the fashion, so that dark red, dark green or dark blue pearls are more or less pricey. Pearl farming is a risky business. The "Service de la perliculture" of French Polynesia established strict criteria to define the classification of the black pearls and to improve the quality of the production. The average time of the pearl cultivation is about 18 months.

Pearl colour is a result of the body colour and the secondary colour (a.k.a. overtones or physical colour). Controlling the pearl colour is one of the main aims in pearl farming; however data about heritability of colours are rare. In experimental grafts, it was shown that the frequency of yellow "akoya" cultured pearls (i.e., cultivated into a Pinctada fucata martensii) was significantly lower in the group produced by grafting mantle 
tissue from the inbred white line than from brown lines (Wada and Komaru 1996). From a study of cultivated $P$. fucata martensii oysters, Velayudhan et al. (1995) concluded that it is possible to improve the quality of pearls and nacre thickness through selective breeding. Using Pinctada maxima, Mamangkey (2009) shows that the colour and the quality of the donor are important. Then, Mamangkey et al. (2010) examine the possible inheritance of the quality of pearls from a single donor. However, no statistical data are available. Some rare experiments took place using xenografts; the mantle piece from a donor species is grafted within a receiver belonging to another species. P. maxima (white to very light gray to brownish yellow - a.k.a golden coloured cultured pearl -) and $P$. margaritifera have been used for such observations to better understand the roles of the donor and receiver (McGinty et al. 2010). The donor species seems to play a major role in the colour of the resulting pearl. In fact, black grafts of $P$. margaritifera implanted in the $P$. maxima result in dark or black coloured cultured pearls.

Mollusc shell colours Pinctada included have been studied using various techniques and criteria. Some commercial societies, as well as gemmological laboratories, provide advices and guides to choose pearls. Others also propose "charts": a picture and a colour designation Some visual categories have been defined by Taylor (2007) for the pearls from Pinctada maxima.

Measurements of the colour in the range of the visible spectra have been made on cultured pearls from $P$. margaritifera with a spectrometer (Dauphin and Cuif 1995; Elen 2002; Huang 2006; Karampelas et al. 2011), but there is no data about the shells (donors or receivers). UV-Visible spectrophotometry has been also used to characterize pearls cultivated into $P$. maxima; but similarly there is no study of the donor or receiver shells related to these pearls (Mamangkey 2009).

Shell and pearl colours of Pinctada were usually explained by the presence of organic pigments. According to the Pinctada species, the colours of the shell and of the resulting pearls differ, and have been attributed to various pigments (Comfort 1949; Sawada 1958, 1961; Akamatsu et al. 1977; Iwashawi and Akamatsu 1994; Zhang et al. 2001, 2009; Karampelas et al. 2011).

In the present study, we have established an objective method to measure the colour of juvenile shells of one breeding family of Pinctada margaritifera in the visible light. The results were compared with the ICI (International Commission on Illumination) diagram. The colours of the shell and of the shell containing the animal are also compared using several wavelengths. If the colour estimation of pearl is difficult, it is even more complex for the juvenile shell. Colour is weak in juvenile shells. Indeed, the juvenile shell is thin so that the colour of the living animal could play a role in the estimation of future colour of the adult shell, then the pearl. Indeed, a precocious selection of the animals according to the colours of the shells would be useful for farming purposes, allowing to breed lineages with dominant and predictable colours. The aim is to study if, at this growth stage, the shell colour is predictable for a potential selection of receiver or donor.

\section{Material and methods}

\subsection{Material}

\subsubsection{Juvenile production in hatchery}

A pure crossing was researched. Oocytes were obtained from one female by lacerating the gonad at the beginning of oocyte release induced by thermal shock. Sperm was obtained simultaneously according to the same procedure. Two hours later, the fertilization rate was evaluated in triplicate on approximately 100 eggs.

\subsubsection{Larval rearing, settlement, pregrowing}

The embryos were transferred into an incubator for 24 hours. D-shaped larvae were then reared for 25 days in a through-flow culture system (Hui et al. 2011). D-shaped larvae were fed using three tropical species of micro-algae: Isochrysis clone T-Iso, Chaetoceros minus and $C$. gracilis. One month after the appearance of eyed-larvae, the seed oysters are pregrown to reach a size higher than $5 \mathrm{~mm}$.

\subsubsection{Sampling}

At 48-50 days old, when colour appears on shell, hundreds of spat belonging to the family "F1010", were sampled to be sent for colour analysis of shell. The average size of the shells is about $2 \mathrm{~mm}$. Spats were placed in Falcon tube $250 \mathrm{ml}$ in $30 \%$ ethanol in sea water.

\subsection{Methods}

\subsubsection{Measurements}

The equipment comprised two main parts linked by an optical fiber bundle which are a microscope-based illumination device and a computer-driven spectral analyzer. Because of the small size and thickness of the shells, a microscope was used. In a first time, the surface was observed before to be selected. The growing edge of the shell was placed on a glass slide on the microscope stage, and was illuminated in transmission mode. The measured area is about $0.5 \mathrm{~mm}$ in diameter and could be reduced if necessary. In a second time, the transmitted light was transferred to the distal end of the optical fibre by a sliding prism.

All spectroscopic analyses were performed with a Spectra 100 spectrometer (Instrument Systems Co., Germany) in a transmittance mode. The entrance and exit slit were $0.1 \mathrm{~mm}$ wide. The scanning unit was based on a grating monochromator, directly driven via a stepping motor. The step width was $1 \mathrm{~nm}$ over the 400-750 $\mathrm{nm}$ range (visible light). Ten successive scans were summed up and recorded. Before the shell measurements, a reference spectrum was done. In transmittance mode, 

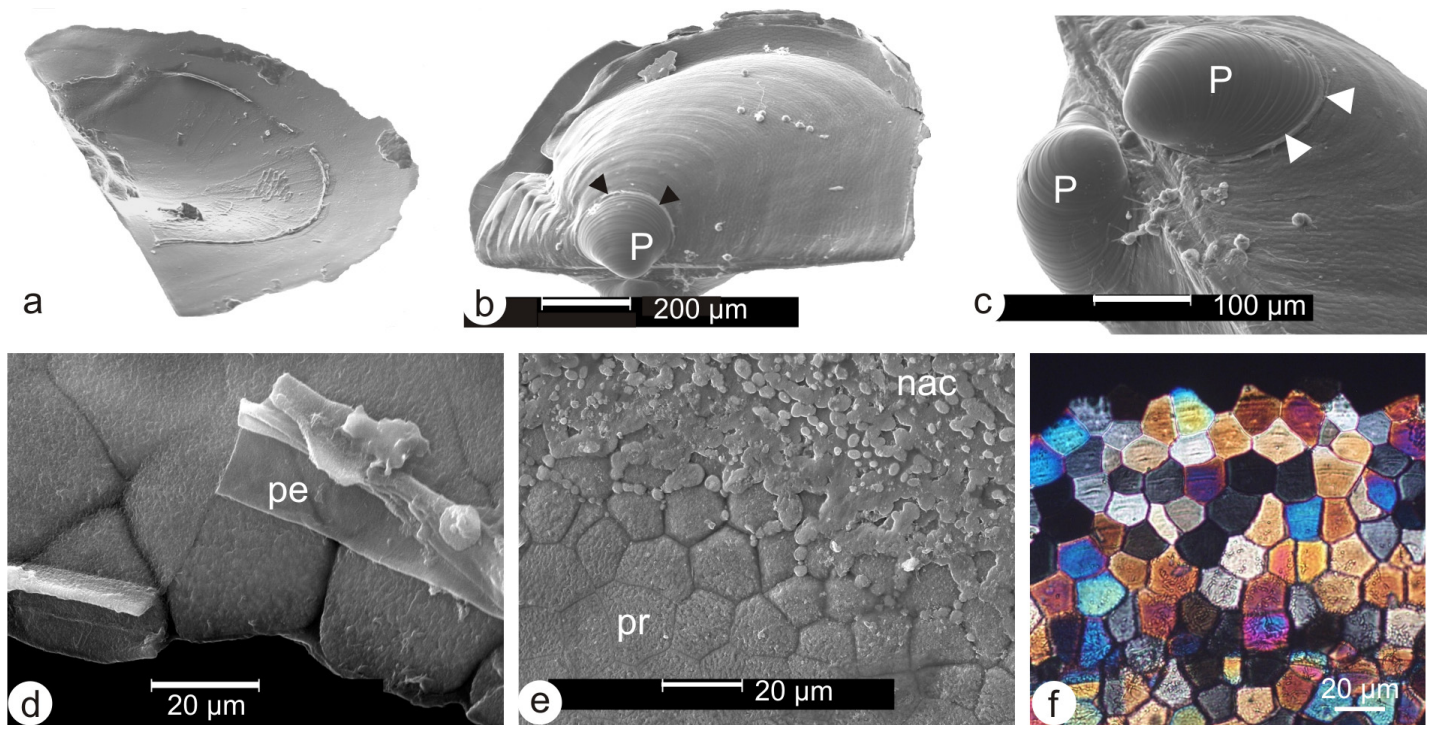

Fig. 1. a-e: Scanning electron microscopy and crossed nicols views of a juvenile shell of Pinctada margaritifera ( $\sim 35$ days old). a: inner view; b, c: outer views; d: outer surface of the growing edge; e: inner surface of the shell showing the prismatic and nacreous layers; f: prismatic layer; P: Prodissoconch, pe: organic pellicle, pr: prism, arrows: boundary between the prodissoconch and the dissoconch (=adult shell).

a reference spectrum is recorded simply by absence of the sample in the beam path. The real scan of the sample is automatically divided by this reference spectrum. The measurements are non destructive, and the samples can be recovered after the experiments. 33 shells were measured.

\subsubsection{Colour analyses}

Two different data files were studied. The first profile results from the ratio between the reference and sample spectra. In such spectra, differences between dark and light shells are not normalized, so they do not correspond to the usual visual evaluation done by people dealing with shells or pearls. From this first data set, the peak value (wavelength for which the transmittance was maximum) was normalized to 1 . This provides normalized intensity ratios (NIR) for every wavelength of the file. In such profiles, the intensity amplitude within a spectrum is reduced, but the differences between dark and light shells are evidenced. A "spectral evaluation graph" including all the data from 400 to $750 \mathrm{~nm}$ was obtained for every sample, using the software of the Spectra 100.

From a practical standpoint, a whole comparative study of all spectra is not easy. In order to define a more convenient control process, maintaining individual chromatic characterization, two methods were used to select values for statistical analyses. The software of the Spectra 100 provides parameters such as the $x, y$ and $z$ values used by the International Commission on Illumination (ICI). $x$ and $y$ are colour coordinates in the chromaticity diagram of the ICI. ICI 1931 "XYZ" colour space was one of the first attempts to produce a colour space based on measurements of human colour perception. $\mathrm{Y}$ is the luminance of a colour, whereas $x$ and $y$ are derived parameters related to the chromaticity of the colour. Despite several ICI diagrams have been created, the 1931 is still the most often used. Thus, these values have been used to compare the colours of the samples. To obtain reliable results, the minimal number of samples providing usable data for the analysis should be five times the number of variables being analyzed. Then, 33 animals and 6 wavelengths corresponding to the ICI primary wavelengths were used for computation process: $430 \mathrm{~nm}$ (blue), $480 \mathrm{~nm}, 530 \mathrm{~nm}, 565 \mathrm{~nm}$ (green), $650 \mathrm{~nm}$ and $700 \mathrm{~nm}$ (red). Normality and Kolmogorov-Smirnov tests were used for the interpretation of the ICI values and principal component analysis (PCA) and factorial discriminant analysis (FDA) for wavelength intensity values. Computer programs XLSTAT and STATGRAPHICS have been used for statistical calculations.

\section{Results}

\subsection{Structure of the shell}

Inner and outer views of a juvenile shell are displayed in Figures $1 \mathrm{a}, \mathrm{b}$. The prodissoconch stage of the shell does not display visible structures, except some growth lines (Figs. 1a, b: P). The boundary between the prodissoconch and the dissoconch (i.e. adult shell) is marked with a distinct line (Figs. 1b, c: arrows). Then the prismatic layer becomes visible (Figs. 1b, c), and forms well-defined polygonal prisms (Figs. 1d-f). At this stage of development, the shell is very thin ( $\sim 10 \mu \mathrm{m}$ thick) and comprises the only prismatic layer. Then, the secretion of the nacreous layer begins, and the aragonitic tablets cover the prismatic units (Fig. 1e). Between these two 

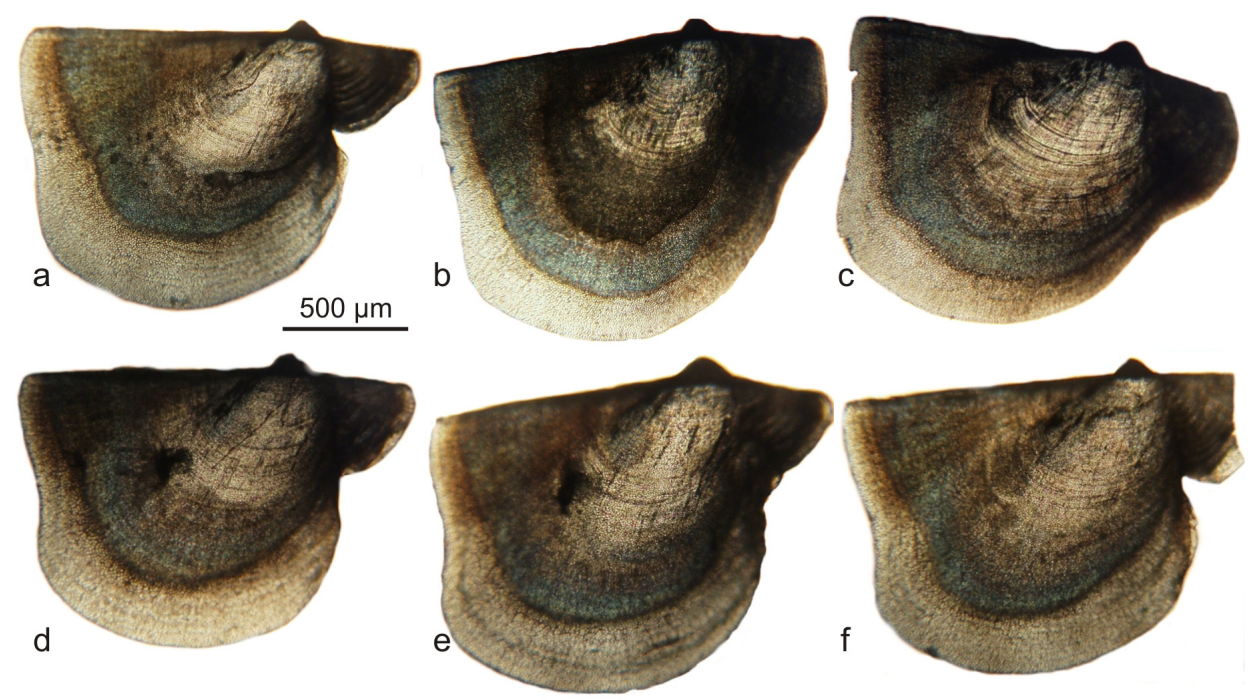

Fig. 2. Outer views of juvenile shells of Pinctada margaritifera (48-50 days old) showing growth layers in the outer prismatic layer. The growing edge is very thin and transparent.
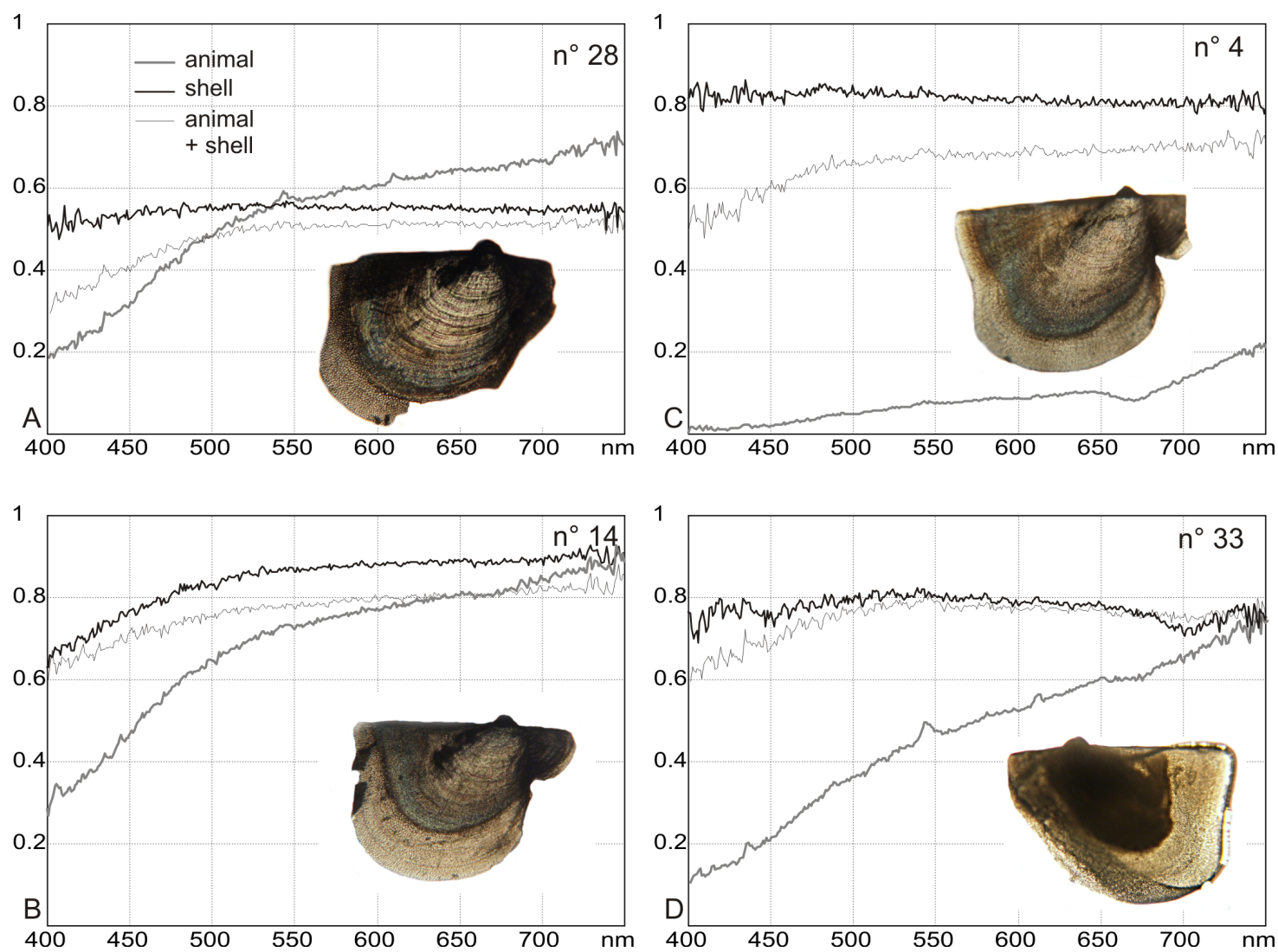

Fig. 3. Four examples of the growing edge profiles (transmittance) of the Pinctada margaritifera shells with and without the animal, and of the animal. Samples $n^{\circ} 4,14$ and 33 are among the most different samples.

main layers, a thick organic envelope and a fibrous aragonitic layer are present (Dauphin et al. 2008, 2010). The outer surface of the growing edge is covered by a thick periostracum. In these juvenile shells, prisms are calcitic monocrystalline units, as shown by crossed nicols observation (Fig. 1f). The average diameter of the 48 days old shells is $2 \mathrm{~mm}$. Outer views show that the darkness of the shell is correlated to the thickness of the nacreous and prismatic layers (Fig. 2). 

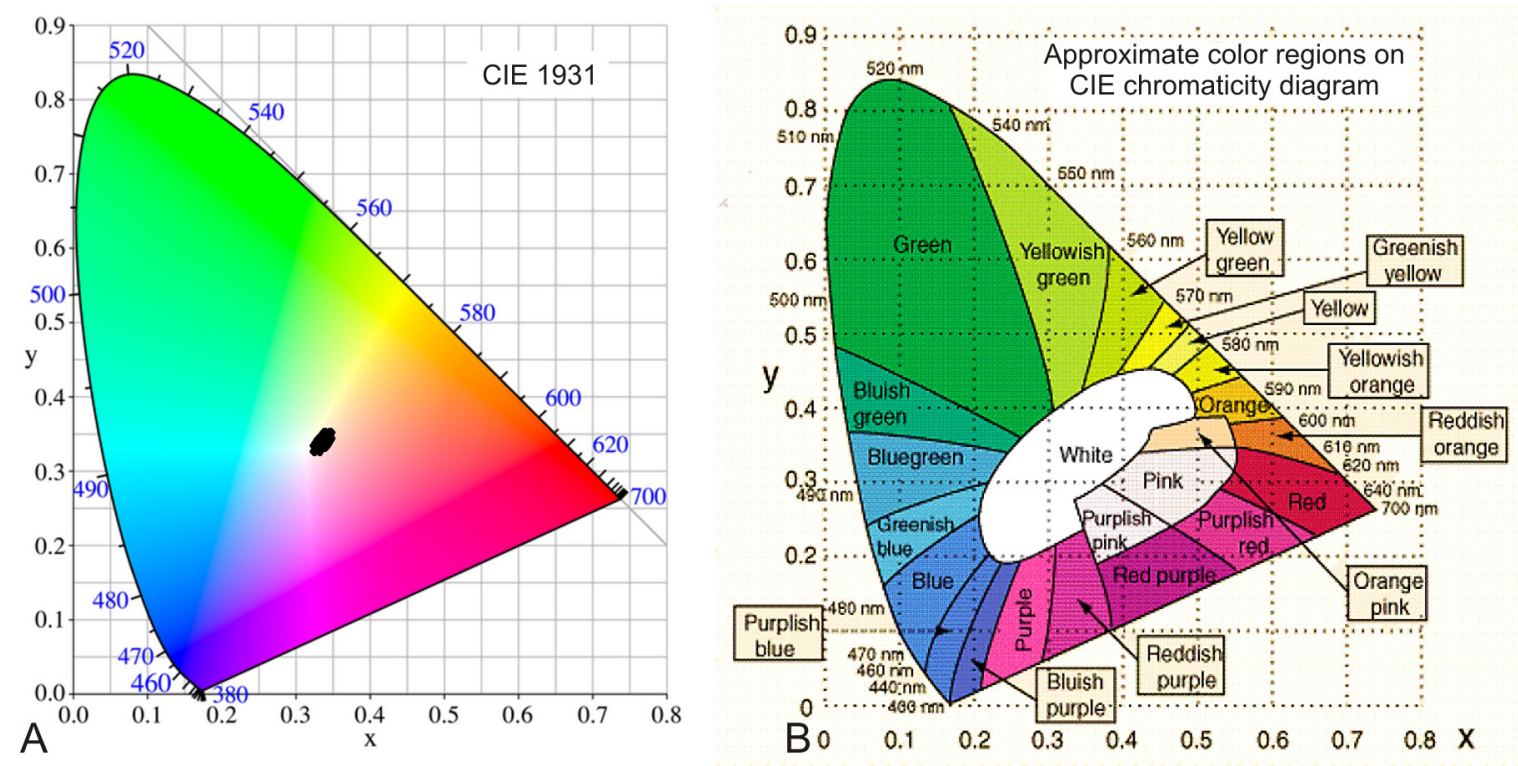

Fig. 4. A: $x$ and $y$ coordinates in the chromaticity diagram of the ICI 1931 space colour, calculated from spectrometric analyses of the shell colour of Pinctada margaritifera, B: colour partition on the diagram.

\subsection{Colourimetric profiles}

Four examples of the profiles of the growing edge of the shell with and without the animal, and of the animal are displayed in Figure 3. Samples $n^{\circ} 4,14$ and 33 are on the external edge of the PCA diagram based on colour of animal + shells (data not shown), whereas sample $n^{\circ} 28$ is in the center part of this area. Thus, samples 14 and 33 are among the most different samples. In all samples, the shell has the "whitest" colour, with an almost flat profile. The animal has a weak blue and a strong red component in all samples. The profiles of samples $n^{\circ} 4$ and 33 show how the animal colours strongly differ, whereas the shell colours are similar. Thus, it will be difficult to select donors from the colour of the animal in order to produce pearls with a dominant colour. The animal + shell profiles depend of the thickness of the animals. In so small animals, during the opening of the shell, it is difficult to avoid wrinkles or folds in the soft tissues, so that the colour appears more or less dark depending of the damages in the mantle.

\subsection{ICI diagram}

Using the $x$ and $y$ values provided by the software of the Spectro100, it is possible to locate the colour of the shells on the ICI 1931 diagram. The growing edge of the shells is a yellowgrey colour (Fig. 2). From the location of the shells in the ICI diagram, we can see that the samples are very similar. In fact, all the individuals are gathered in a small area (Fig. 4A), so that they are indistinct. The black zone created by the adjacent points (=shells) hides the colour, but they are around the achromatic point. The achromatic point is also called white point. On a graph showing colour partition in the graph, the growing edges of the shell are in the "white" part (Fig. 4B). Kolmogorov-
Smirnov test is a test for the equality of one-dimensional probability distributions (one-sample K-S test). The K-S test has the advantage of making no assumption about the distribution of data: it is a non-parametric test. Histograms and normality curves and tests of $x$ and $y$ values, as well as KolmogorovSmirnov data are indicative of their normal distribution (Fig. 5). They also confirm that $x$ and y averages are similar $(x=0.337$, $y=0.339)$, with a low variability $(x, \sigma=0.004 ; y, \sigma=0.004)$. Histograms also show that the average and extreme values of $x$ and $y$ are in the white zone of the ICI diagram (Fig. 4B), so that no distinct colour is visible in the shells.

\subsection{Multivariate analyses}

To understand the influence of the animal on a naked eye evaluation of the colour of the shell, a principal component analysis was done. A set of 33 shells + animals, then the same shells without animals were measured, using 6 wavelengths.

Principal component analysis (PCA) is a mathematical transformation to convert a set of observations of possibly correlated variables into a set of values of uncorrelated variables; these "secondary" variables are called "principal components". PCA is a simple, non-parametric method of extracting relevant information from confusing data sets, by reducing data dimensionality by performing a covariance analysis between factors.

The correlation matrix shows that the wavelengths are correlated. This is shown on the graph of the variables and individuals (Fig. 6). The first principal axis contains $97.1 \%$ of the total variance, whereas axes 2 and 3 represent only $2.7 \%$ and $0.12 \%$ respectively. Thus, a graph using the first two factors is indicative of the most part of the variability. Along the first principal component, samples are sorted according to the 

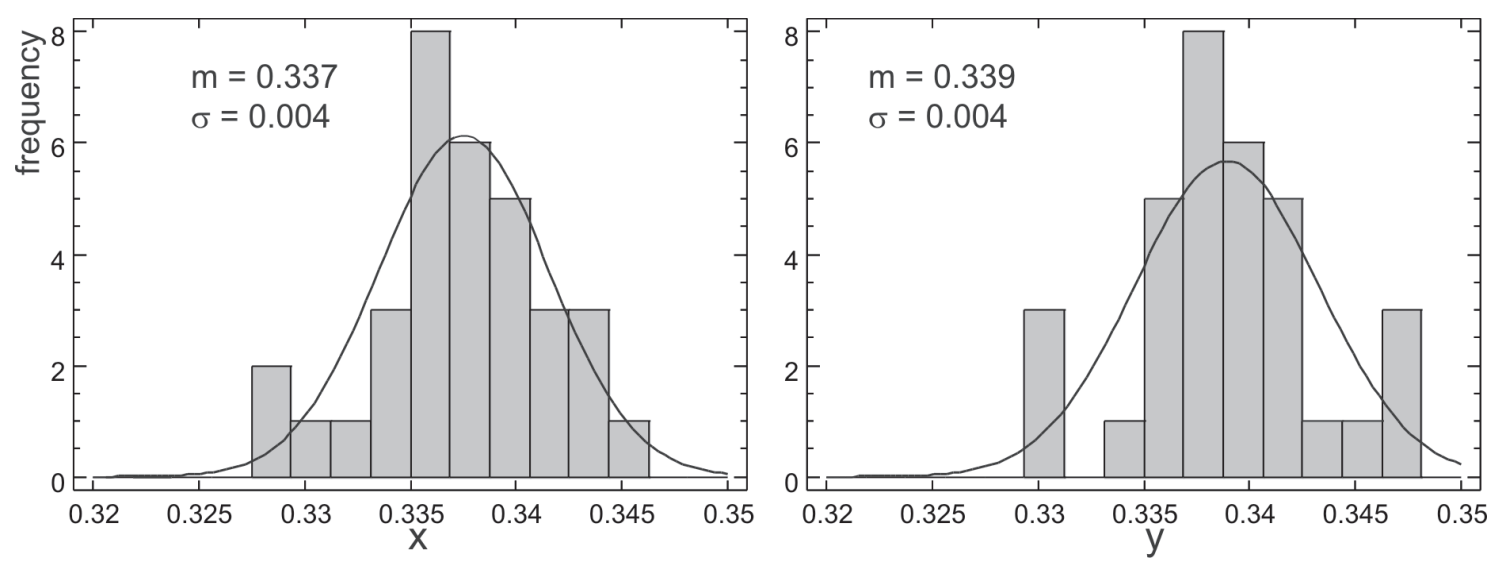

Fig. 5. Histograms and normality curves of $x$ and $y$ coordinates of the ICI 1931 space colour, from spectrometric analyses of the shell colour of Pinctada margaritifera, showing their normal distribution. $x$ and $y$ averages are similar with a low variability.

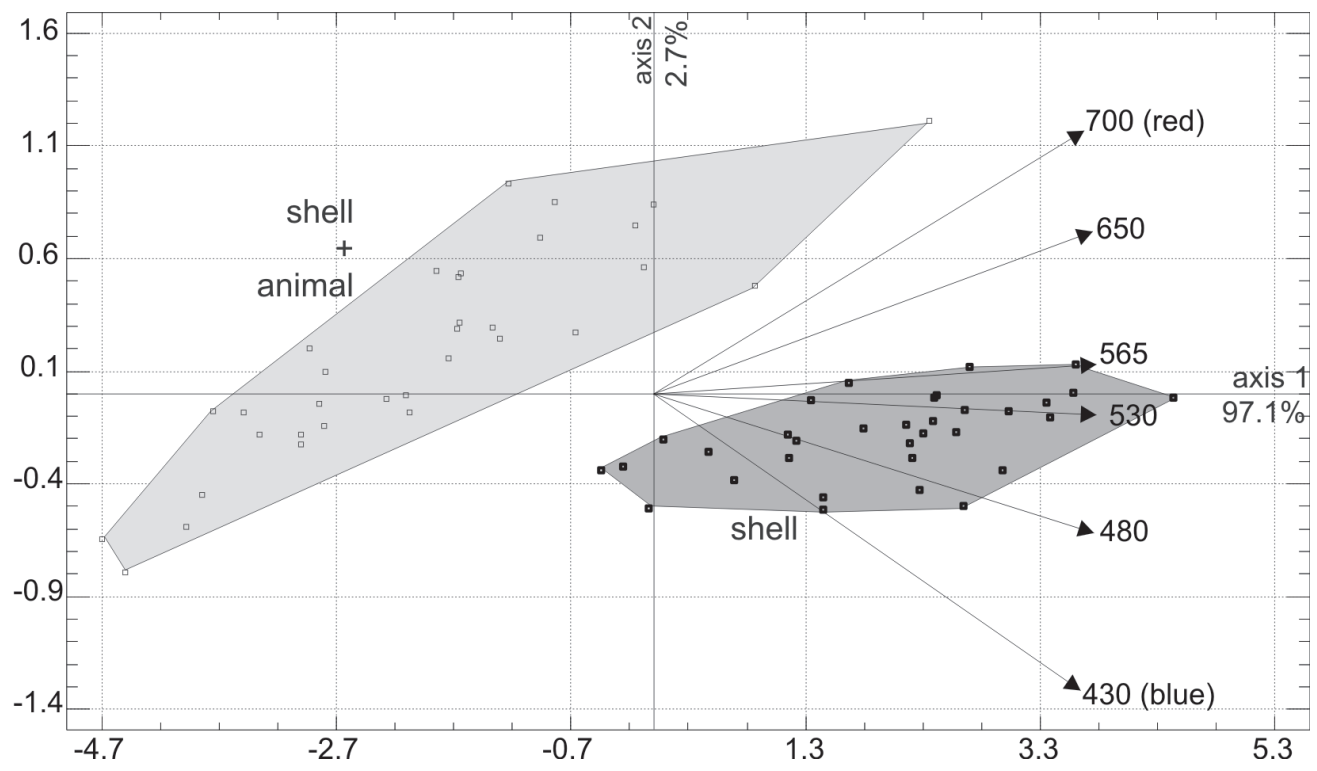

Fig. 6. Principal component analysis graph showing the variables: 6 wavelengths at 430, 480, 530, 565, 650 and 700 nm, and the Pinctada margaritifera samples: colour of 33 shells + animals. Shells and animal + shell sets are mainly "grey", animal + shell being somewhat redder. Shell colour is more homogeneous (smaller area) than that of animal + shell. Along the first principal component, samples are sorted according to the intensity of $530 \mathrm{~nm}$ and $565 \mathrm{~nm}$ wavelengths ( green).

intensity of $530 \mathrm{~nm}$ and $565 \mathrm{~nm}$ wavelengths ( green) (Fig. 6). However, the eigenvectors of all the variables are between 0.399 $(430 \mathrm{~nm})$ and 0.414 (530 and $565 \mathrm{~nm})$. In the second principal component the samples are sorted according to the intensity of $430 \mathrm{~nm}$ ( blue), opposed to $700 \mathrm{~nm}$ and $650 \mathrm{~nm}$ ( red). The set composed of shells + animals has a larger surface than that of the shells. This shows that the colour of shells is less variable. The colour of the animals + shells is darker, mainly because of the thickness of such samples, but the main characteristics are similar.

In order to test a possible significant difference between groups, and to know to which group a new observation belongs, a discriminant function analysis (DFA) was done using the same set of wavelengths. A class variable (presence or absence of the soft tissues) was added. So, the case of dichotomous groups is simple and the predictor variable is single. At issue is whether the role of the soft tissues will influence a naked eye evaluation of the juvenile animals. Using DFA, $100 \%$ of the samples are correctly classified.

For a better evaluation of the colour of every sample, a star plot was done using the same variables (Fig. 7). In this diagram, the length of a radius is proportional to the intensity of the variable, which is a wavelength. The largest polygons are indicative of white samples. The shapes of the stars corresponding to the shells seem to be similar. They usually have a large radius showing that the colour is in the white region. However, the range of 


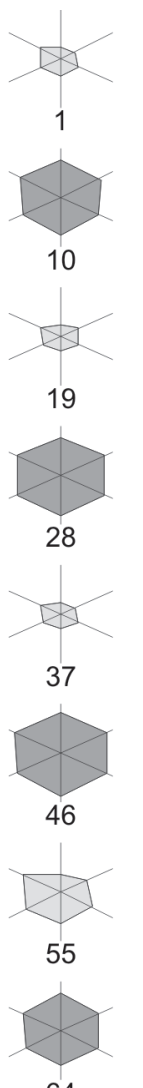

64

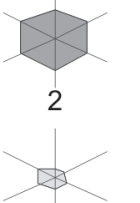

11

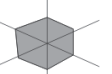

20

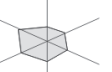

29

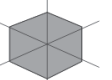

38

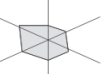

47

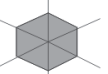

56

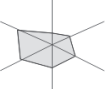

65

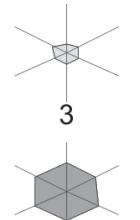

12

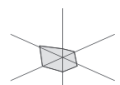

21

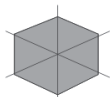

30

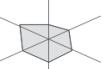

39

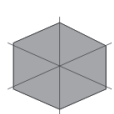

48

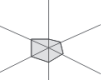

57

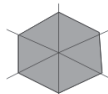

66

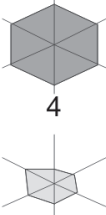

13

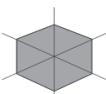

22

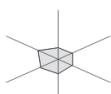

31

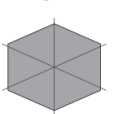

40

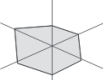

49

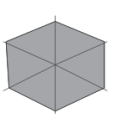

58

shel
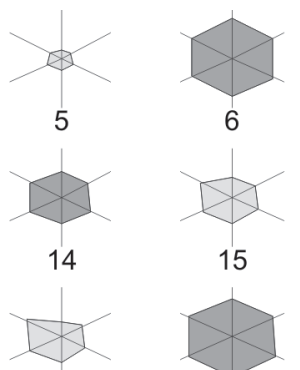

23

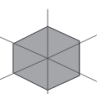

32

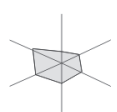

41

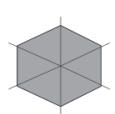

50

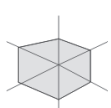

59
15

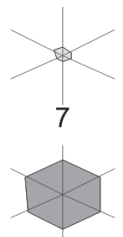

16

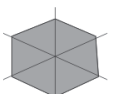

24

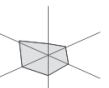

33

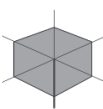

42

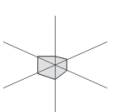

51

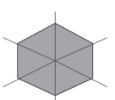

60

25

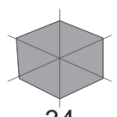

34

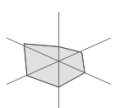

43

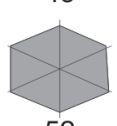

52
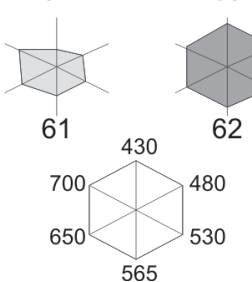

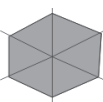

8

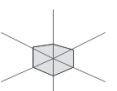

17

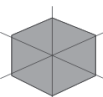

26

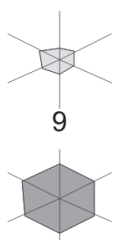

18

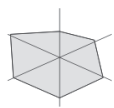

27

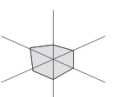

35
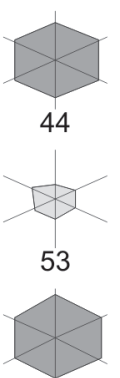

62

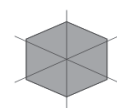

36

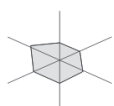

45
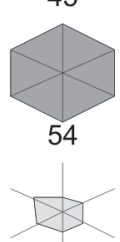

63

Fig. 7. Star plots representative of shell and shell + animal colour in Pinctada margaritifera juveniles. The length of a radius is proportional to the intensity of the variable (=wavelength). Animal + shell set is darker than the shell only.

"darkness" is high as shown by the comparison of individuals: sample 20 is one of the darkest shells, whereas sample 54 is one the of whitest (Fig. 7). The shapes of the stars corresponding to the animals + shells are more diverse, and the radiuses are shorter. In most animal + shell samples, the $700 \mathrm{~nm}$ radius $(\sim$ red $)$ is the longest, whereas the $430 \mathrm{~nm}$ radius ( blue) is the shortest among the 6 variables (Fig. 7). Thus, a sample including shell + animal seems redder than the only shell. PCA results are confirmed, but the characteristics of every sample are visible.

\section{Discussion}

From the above results, two main topics can be discussed: (1) the relevance of the used methods for measurements and statistics, (2) the relevance of the colour measure of juvenile shells (48 days old).

\subsection{Relevance of the methods}

With the advent of digital photographic systems and software, it is now fast, easy and cheap to record images of colour objects, living animals included. In spite of the ready availability of these methods, only few attempts have been made to apply them to mollusc shells. A method has been developed to measure colours in visible light, based on digitalized images and the MKO RGB colorimetric system (Kozminskii and Lezin 2006). It has been then applied in the gastropod Littorina to study the distribution of pigments (Kozminsky and Lezin 2007). Pinctada is not the only molluscan shell with colours. Most shells have colour patterns, but the origin of the colour is not well known. Several pigments have been described in various taxa used different techniques (Zhang et al. 2001; Withnall et al. 2003; Brink and Van Der Berg 2005; Zheng et al. 2010; Hedegaard et al. 2006; Trinkler et al.2011). Up to now, only one method has been used for a set of samples. Thus, the comparability of these techniques remains a questioned issue. Actually, the choice of the techniques strongly depends on the problem, and on the nature of the sample: is the sample a living organism? Is it needed to recover the sample for another experiment?

Detailed measurements in the visible light spectra and statistical analyses are very rare. The range of wavelengths used in this experiment is that of the visible light for human eye. Neither ultraviolet nor infrared wavelengths have been selected, in order to establish criteria potentially easily useful in farms and hatcheries.

There is no general agreement about the origin of the colour. Dubois (1909) has described black pearls in Pinctada from 
Tahiti, but also in Pinna nobilis with a white nacre. In natural pearls, the pearl colour is clearly related to that of the nacreous layer of the shell. Colour is due to pigments in the organic component named "conchyolin". In this study, the colour of the prismatic layer is not taken into account. More recently, Xinnong et al. (1997) report "that the $\mathrm{CaCO}_{3}$ crystal orientation is responsible for the colour of nacreous layer or pearl" in Hyriopsis cumingii. Karampelas et al. (2007) show that the various colours of the pearls built by the same species are due to different ratios of organic pigments. It is probable, that both components, mineral and organic are involved in colours. The thickness and structure of the nacreous layer are repeatedly evoked (Liu et al. 1999). However, a mild decalcification process shows that the organic membranes surrounding the structural units (prisms, tablets) are colored, as the soluble organic matrices (unpublished data).

The method we have used in this experiment does not provide data about the origin of colour. However, it has several practical advantages: (i) samples are intact after the measurement; (ii) thus, it can be used on living animals or expansive samples such as pearls; (iii) the size of the measured spot is variable; (iv) it does not require biochemical skills.

\subsection{Relevance of colour measurement in juvenile shells}

Only a few studies are devoted to the colour analyses in mollusc shells. Among them, some are concerned with patterns (Ermentrout et al. 1986), while others study the relationships between colour and genes (Atkinson and Warwick 1983; Adamkewicz and Castagna 1988; Peignon et al. 1995; Rodrigues and Absalao 2005; Jackson et al. 2006), or colour and diet (Reimchen 1979; Manriquez et al. 2009). Genetics, diet and environment are described as factors influencing colour in a given species. However, very few study seems to be dedicated to the emergence of colour in juvenile shells, the possible changes during growth or the colour heritability through generations (Sanford et al. 2009).

In this study, we have worked on dead molluscs and their shells. It would be also possible to analyze colours in living animals with spectrometry in hatcheries. The main problem would be the small size of the juvenile animals. In fact, it is not possible to label them to be able to measure again after some months. Thus, monitoring the evolution of colours in a given animal during growth is currently impossible. Statistical analyses would ensure to obtain data about the emergence and changes in shell colour during growth. Despite only one family was studied to-date, a colour trend is not visible, and there is a large variability between the whitest and darkest shells (Fig. 7). Moreover, the recovery of living animals would require analyzing the colour of the shell + animal. Our study shows that the presence of the soft tissues modifies the measured data.

Up to now, no relevant data are available, to predict the colour of an adult shell from a juvenile one which is 48 days old. So, a subsequent selection of animals based on colour measured at this age is does not seem pertinent even with measurements. It seems even more difficult in farms. It is why, the spectrometric method developed in this study will be applied on juveniles from the same family (F1010), but which are about 70 and 110 days old (growth stage with periostracum development). This work will allow following the apparition of the colour with time.

\section{Conclusion}

The spectrometric method developed in this study is able to characterize the colour of shell and animal + shell of Pinctada margaritifera. ICI 1931 diagram of the shell shows that the colour is weak. Multivariate analyses are in accordance with ICI results: the colour is weak or absent. Thus, the selected wavelengths can be used to characterize older shells. The two main results obtained in this study are (1) the colour of animal + shell is darker and redder than the colour of the shell, (2) at about 48 days, no relevant data are available to predict the colour of an adult shell from a juvenile one. Despite there is a strong commercial interest to select animals as soon as possible to produce "pure colour lineages", the apparent colour visible at this growth stage is not indicative of the colour of the adult shells.

Acknowledgements. This study was funded by the collaborative project (GDR ADEQUA) supported by the "Service de la perliculture" of French Polynesia and IFREMER. The authors are also grateful to referees for their valuable contributions.

\section{References}

Adamkewicz L., Castagna M., 1988, Genetics of shell colour and pattern in the bay scallop Argopecten irradians. J. Hered. 79, 14 17.

Akamatsu S., Komatsu H., Koizumi C., Nonaka J., 1977, A comparison of sugar components of yellow and white pearls. Nippon Suisan Gakkaishi 43, 773-777.

Atkinson W.D., Warwick T., 1983, The role of selection in the color polymorphism of Littorina rudis Maton and Littorina arcana Hannaford-Ellis (Prosobranchia: Littorinidae). Biol. J. Linn. Soc. 20, 137-151.

Brink D.J., Van Der Berg N.G., 2005, An investigation of green iridescence on the mollusc Patella granatina. J. Phys. D Appl. Phys. 38, 338-343.

Cochennec-Laureau N., Montagnani C., Saulnier D., Fougerouse A., Levy P., Lo C., 2010, A histological examination of grafting success in pearl oyster Pinctada margaritifera in French Polynesia. Aquat. Living Resour. 23, 131-140.

Comfort A., 1949, Acid-soluble pigments of molluscan shells. 2. Pigments other than porphyrins. Biochem. J. 45, 199-204.

Dauphin Y., Ball A.D., Cotte M., Cuif J.P., Meibom A., Salomé M., Susini J., Williams C.T., 2008, Structure and composition of the 
nacre - prism transition in the shell of Pinctada margaritifera (Mollusca, Bivalvia). Anal. Bioanal. Chem. 390, 1659-1169.

Dauphin Y., Brunelle A., Cotte M., Cuif J.P., Farre B., Laprévote O., Meibom A., Salomé M., Williams C.T., 2010, A layered structure in the organic envelopes of the prismatic layer of the shell of the pearl oyster Pinctada margaritifera (Mollusca, Bivalvia). Microsc. Microanal. 16, 91-98.

Dauphin Y., Cuif J.P., 1995, Trichromatic characterization of the "black pearls" from aquaculture centers of French Polynesia. Aquaculture 133, 113-121.

Dubois R., 1909, Contribution à l'étude des perles fines, de la nacre et des animaux qui les produisent. Ann. Univ. Lyon, N.S. Sciences, Médecine 29, 1-127.

Elen S., 2002, Identification of yellow cultured pearls from black-lipped oyster Pinctada margaritifera. Gems Gemmol. 38, 66-72.

Ermentrout B., Campbell J., Oster G., 1986, A model for shell patterns based on neural activity. Veliger 28, 369-388.

Hedegaard C., Bardeau J.F., Chateigner D., 2006, Molluscan shell pigments: an in situ resonance Raman study. J. Moll. Stud. 72, $157-162$.

Huang Y.L., 2006, Visible absorption spectrum representation of Tahitian black pearls and treated pearls. J. Gems Gemmol., 8, 5-8.

Hui B., Vonau V., Moriceau J., Tetumu R., Vanaa V., Demoy-Schneider M., Suquet M., Le Moullac G., 2011, Hatchery-scale trials using cryopreserved spermatozoa of black-lip pearl oyster, Pinctada margaritifera. Aquat. Living Resour. 24, 219-233.

Iwahashi Y., Akamatsu S., 1994, Porphyrin pigment in black-lip pearls and its application to pearl identification. Fish. Sci. 60, 1, 69-71.

Jackson D.J., McDougall C., Green K., Simpson F., Wörheide G., Degnan B.M., 2006, A rapidly evolving secretome builds and patterns a sea shell. BMC Biol. doi:10.1186/1741-7007-4-40.

Karampelas S., Fritsch E., Gauthier J.P., Hainschwang T., 2011, UVVIS-NIR reflectance spectroscopy of natural-color saltwater cultured pearls from Pinctada margaritifera. Gems Gemmol. 47, 31-35.

Karampelas S., Fritsch E., Mevellec J.Y., Gauthier J.P., Sklavounos S., Soldatos T., 2007, Determination by Raman scattering of the nature of pigments in cultured freshwater pearls from the Mollusk Hyriopsis cumingi. J. Raman Spectr. 38, 217.230.

Kozminskii E.V., Lezin P.A., 2006, Method of color measurements of the elements of color in Gastropods shell. Russ. J. Mar. Biol. 32, 316-318.

Kozminsky E.V., Lezin P.A., 2007, Distribution of pigments in the shell of the Gastropod Littorina obtusata (Linnaeus, 1758). Rus. J. Mar. Biol. 33, 238-244.

Liu Y., Shigley J.E., Hurwitt K.N., 1999, Iridescence color of a shell of the mollusk Pinctada margaritifera caused by diffraction. Opt. Express 4, 177-182.

Mamangkey N.G.F., 2009, Improving the quality of pearls from Pinctada maxima. Ph.D. thesis, J. Cook University.

Mamangkey N.G.F., Agatonovic S., Southgate P.C., 2010, Assessing pearl quality using reflectance UV-Vis spectroscopy: does the same donor produce consistent pearl quality? Mar. Drugs 8, $2517-2525$.
Manriquez P.H., Lagos N.A., Jara M.E., Castilla J.C., 2009, Adaptive shell color plasticity during the early ontogeny of an intertidal keystone snail. Proc. Natl. Acad. Sci. USA 106, 16298-16303.

McGinty E.L., Evans B.S., Taylor J.J.U., Jerry D.R., 2010, Xenografts and pearl production in two pearl oyster species, $P$. maxima and $P$. margaritifera: Effect on pearl quality and a key to understanding genetic contribution. Aquaculture 302, 175-181.

Peignon J.M., Gérard A., Naciri Y., Ledu C., Phélipot P., 1995, Analyse du déterminisme de la coloration et de l'ornementation chez la palourde japonaise Ruditapes philippinarum. Aquat. Living Resour. 8, 181-189.

Reimchen T.E., 1979, Substratum heterogeneity, crypsis, and color polymorphisms in an intertidal snail (Littorina mariae). Can. J. Zool. 57, 1070-1085.

Rodrigues L.R.G., Absalao R.S., 2005, Shell colour polymorphism in the chiton Ishnochiton striolatus (Gray, 1828) (Mollusca: Polyplacophora) and habitat heterogeneity. Biol. J. Linn. Soc. 85, 543-548.

Sanford E., Camara M.D., Langdon C.J., 2009, Heritability of shell pigmentation in the Pacific oyster, Crassostrea gigas. Aquaculture 286, 211-216,

Sawada Y., 1958, Biochemical studies on the pearl oyster, Pinctada martensii (Dunker). Porphyrin pigments of the shell. Bull. Nat. Pearl Res. Lab. 41, 335-339.

Sawada Y., 1961, Studies on the yellow pigment of pearl. Bull. Nat. Pearl Res, Lab. 88, 865-869.

Taylor J.J.U., 2007, Atlas south sea pearl grading and coding matrix. Internal Company document.

Trinkler N., Bardeau J.F., Marin F., Labonne M., Jolivet A., Crassous P., Paillard C., 2011, Mineral phase in shell repair of Manila clam Venerupis philippinarum affected by the brown ring disease. Dis. Aquat. Org. 93, 149-162.

Velayudhan T.S., Dharmaraj S., Victor A.C.C., Chellam A., 1995, Colour and thickness of nacre in four generations of Indian pearl oyster, Pinctada fucata (Gould) produced in the hatchery. Mar. Fish, Inf. Serv., Techn. Exter. Ser., 137, 3-6.

Wada K.T., Komaru A., 1996, Color and weight of pearls produced by grafting the mantle tissue from a selected population for white shell color of the Japanese pearl oyster Pinctada fucata martensii (Dunker). Aquaculture 142, 25-32.

Withnall R., Chowdhry B.Z., Silver J., Edwards H.G., de Oliveira L.F.C., 2003, Raman spectra of carotenoids in natural products. Spectrochim. Acta, A Mol. Biomol. Spectrosc. 59, 2207-2212.

Xinnong J., Junying Z., Xuehong X., 1997, The relationship between nacreous layer color and $\mathrm{CaCO}_{3}$ crystal orientation. Wuhan Univ., J. Nat. Sci. 2, 507-508.

Zhang G., Xie X., Wang Y., 2001, Raman spectra of nacre from shells of main pearl-culturing mollusks in China. Spectrosc. Spectr. Anal. 21, 193-196.

Zhang W.G., Wang G., Yan J., Li H.X., Zhang G.S., 2009, Unique optical reflection spectra of bivalve nacre and its origin. Spectrosc. Spectr. Anal. 29, 1186-1188.

Zheng H., Liu H., Zhang T., Wa,ng S., Sun Z., Liu W., Li Y., 2010 Total carotenoid differences in scallop tissues of Chlamys nobilis (Bivalve: Pectinidae) with regard to gender and shell colour. Food Chem. 122, 1164-1167. 